\title{
The Success and Failure in the Finnish Labor Market of Different Demographic Groups ${ }^{1}$
}

\author{
TOR ERIKSSON
}

\section{Introduction}

Recently economists have devoted a lot of energy on studies and debates on the interpretation of unemployment. The central concern has been the notion that unemployment figures have ceased to reflect properly the "true» excess supply of labor or the »true» success of the labor force in the market. The two major themes have been whether the unemployment statistics should be deflated to account for changes in the demographic composition of the labor force and whether unemployment has changed because social security systems have changed. Studies of these and other related questions have more carefully than before examined the behavioral relationships.

The basic idea in a series of papers by Clark and Summers $(1979,1981,1982$ a, b, c) is, however, that focusing on the flows into and out of unemployment may give a too partial or in fact flawed picture of the dynamics of the labor market, and consequently also lead to wrong conclusions regarding the nature and causes of unemployment. In particular they have demonstrated that neglect of the flows of individuals between not in the labor force state and (employment or) unemployment exaggerates: 1 . the unemployed's success of finding jobs, 2. the limited scope for aggregate demand policies, and 3. the disincentive effects of unemployment insurance systems on unemployment.

The pervasive implications of taking into account the simultaneous interactions between all flows in the labor market, and not exclusively those from or into unemployment, is also emphasized in an extensive survey article by Ehrenberg (1980). ${ }^{2}$

It has also become increasingly clear that speaking of »the" unemployment rate or »the» labor force participation ratio is not particularly revealing as both the levels and the magnitude of the fluctuations around them differ substantially across subgroups in the population. This is especialy the case with age-sex groups considered below. Looking at the success of demographic groups in the labor market also illuminates the fact that "the unemployment problem" is full of nuances.

Now, as data on flows between employment, unemployment and not in the labor force states are not available for Finland the afore-mentioned issues cannot be adressed directly. However, some insights may be gained also by indirect, more traditional, methods used in this paper. As will become apparent though, they are certainly not substitutes for analyses of flow data, and the results of this paper should, accordingly, be interpreted as suggestive.

In the following section we introduce and estimate a simple model of both employment and labor force participation behavior of different demographic

1 This is a shortened version of the paper presented at the symposium. Comments by Eskil Wadensjö are gratefully acknowledged.

2 See also, e.g., Kiefer and Neumann (1982), Burdett et. al. (1984), and Weiner (1982). 
groups. The focus is on differences between the groups in the simultaneous cyclical fluctuations in these two variables and the pattern of unemployment variation of age-sex groups which arises from differences in participation and employment responses is examined.

The third section utilizes the same apparatus to scrutinize long-run changes in the levels of age-sex specific unemployment rates. Here, as in the foregoing section, the impact of the institutional change brought about by the 1972 Employment Law is discussed. The last section contains some conclusions and remarks on their implications.

\section{Cyclical changes in different demographic groups' success in the labor market}

It is commonly observed that although unemployment rates of different demographic groups move together over the business cycles they do differ substantially in the levels about which they fluctuate as well as in their cyclical behavior. The approach in this paper is the almost trivial observation that the unemployment rate may provide us with a misleading picture of people's success and failure in the labor market, and that this is especially the case when we are looking at unemployment rates of different groups in the labor force. Naturally, this is because a reduction in the unemployment rate may be caused by a decrease in labor force participation rather than by an increase in employment. Likewise, a group's unemployment rate may increase while its members' employment at the same time is increasing because its labor force participation rate is expanding proportionately faster. Nevertheless, this simple fact is often neglected or abstracted from. The analysis carried out here will concentrate on both unemployment rates and labor force participation rates for different demographic groups, i.e., we shall consider the issue whether changes in unemployment rates are brought about by changes in participation or in employment, or both. For this purpose we focus on the employment to population ratio, E/P, for each demographic category. Changes in $\mathrm{E} / \mathrm{P}$ consist of two components:

1. a change in the proportion of individuals outside the labor force, and

2. a change in the fraction of the labor force out of jobs.

In symbols we have

(1) $\mathrm{E} / \mathrm{P}=(\mathrm{L} / \mathrm{P})(\mathrm{E} / \mathrm{L})=(\mathrm{L} / \mathrm{P})(1-(\mathrm{U} / \mathrm{L}))$,

or cast in logaritmic differences,

(2) $d \ln (E / P)=d \ln (L / P)+d \ln (1-(U / L))$,

where $\mathrm{U}$ and $\mathrm{L}$ stand for unemployment and labor force, respectively.

The components in the identity (1) for the total Finnish population, aged 15 to 64 , convey a picture of relatively stable development characterized mainly by cyclical variations. However, aggregation of the sexes masks the fact that considerable secular changes have taken place. As disaggregation is carried further by age this picture becomes even more pronounced.

Inspections of data for age/sex. groups bear evidence of a secular growth in male youth as well as nearly all female unemployment rates. For teenagers of both sexes and old women this is accompanied by a secular decrease in participation and hence in the employment ratios, too. The utmost noteworthy feature is that for adult females participation rates have been increasing simultaneously, and moreover, to the extent that their employment ratios have been increasing as well. 
The remarkable changes in participation of age-sex groups are also borne out by Figure 1, in which the participation rates by age in 1965, 1970, 1975, and 1980 males and females, are given. Here we may note for males, that the bell shape has become more distinct over time as the tails have lost a lot of their weight. The same is true also for females. In 1965 the distribution was M-shaped, although far from pronounced, but during the 70 s the $» M »$ vanishes almost completely, giving rise to a bell similar to that of males.

As noted above it is clear that there are quite significant secular changes in both components in $\mathrm{E} / \mathrm{P}$ for virtually all age groups, except prime males. Moreover, for some groups at least, there also appears to be important cyclical fluctuations in labor force participation. In order to discern the contribution of the different components we shall next estimate an empirical model which captures

Fig u r e 1. Participation rates by age and sex
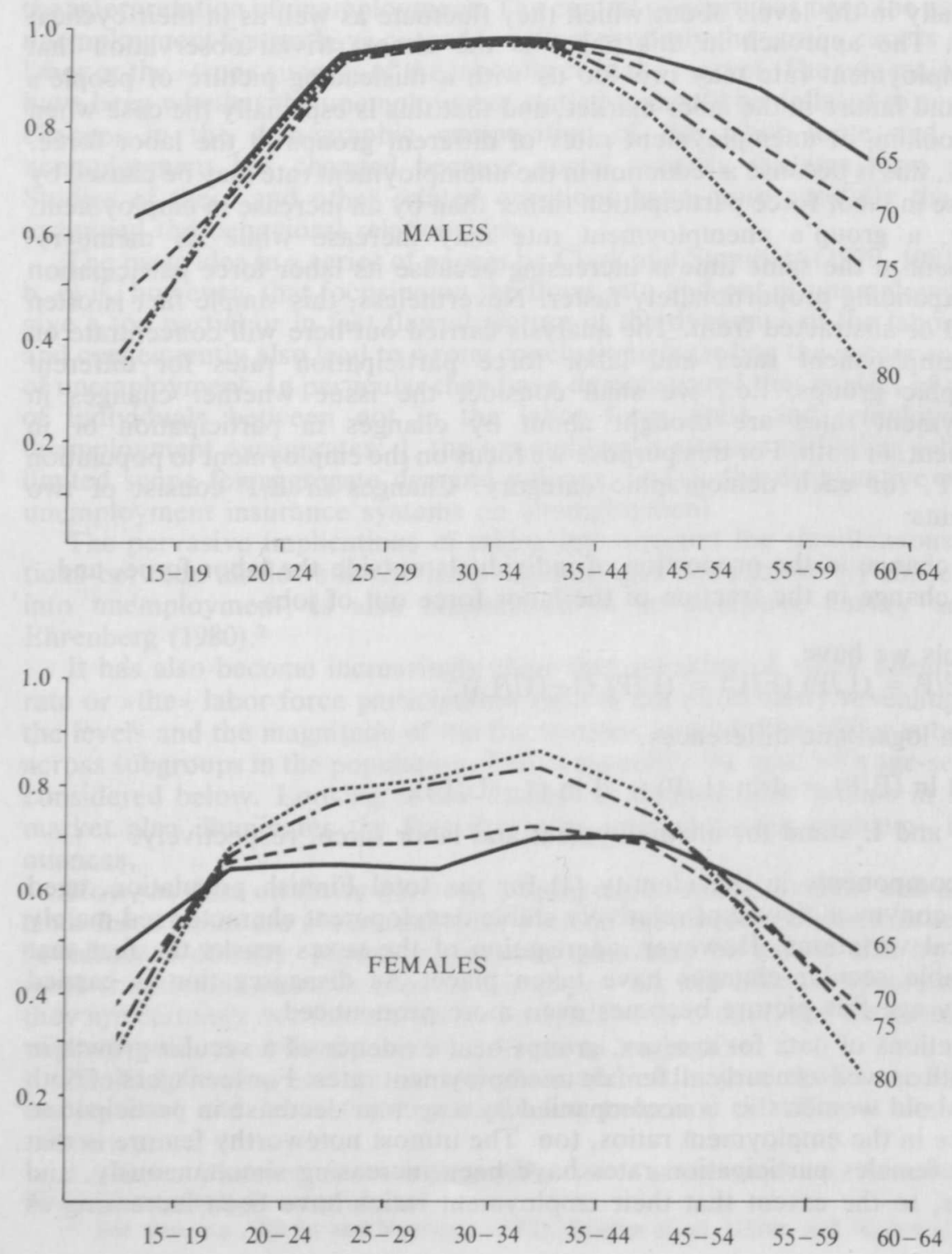
the link between labor force participation and unemployment dynamics. The basic model, which is essentially the same as the ones utilized by e.g. Feldstein (1973), Clark and Summers (1981), (1982a), and Freeman and Medoff (1982), consists of two equations, one describing the behavior of participation for each agesex category, and one describing cyclical and other influences on group unemployment rates (here in fact their complements will be utilized). The model, which will be estimated on annual data for $1965-81^{3}$, is

$$
\begin{aligned}
& \text { (3) } \ln (\mathrm{L} / \mathrm{P})_{\mathrm{j}, \mathrm{t}}=\alpha_{0}+\left(\alpha_{1}+\alpha_{2} \mathrm{D}\right) \mathrm{PU} \mathrm{U}_{\mathrm{t}}+\left(\alpha_{3}+\alpha_{4} \mathrm{D}\right) \mathrm{T}+\epsilon_{\mathrm{t}} \\
& \text { (4) } \ln (1-(\mathrm{U} / \mathrm{L}))_{\mathrm{j}, \mathrm{t}}=\beta_{0}+\left(\beta_{1}+\beta_{2} \mathrm{D}\right) \mathrm{PU}_{\mathrm{t}}+\left(\beta_{3}+\beta_{4} \mathrm{D}\right) \mathrm{T}
\end{aligned}
$$

where PU is the unemployment rate of males aged 35 to 44 years, D is a dummy variable - the rationale for which is explained below - equal to zero up to 1971 and unity thereafter, and T is time. Hence DT is another trend beginning in 1972 . $\mathrm{PU}$ is used here as the aggregate demand variable since it is very unlikely to have been influenced by changes in participation and the secular factors considered for the other age groups. The auxiliary variables, T and DT, are included to reflect slowly changing factors. Among these are: ${ }^{4}$ (i) changes in the demographic structure, (ii) extension of higher education, (iii) declining fertility rates, (iv) the contraction of agriculture and expansion of the service sector, (v) emigration, and (vi) changing attitudes towards working mothers, extended municipal child care, etc.

Since these factors cannot be assumed to be strictly exogenous w.r.t. the participation rates and employment ratios $^{5}$ the trends simplify matters greatly ${ }^{6}$. The model is also bereft of the additional complexities which would arise from recognition of real wage and expected real wage variables. Thus, participation as well as employment are assumed to be primarily determined by job availability.

The dummy D is introduced to pick up possible effects of the Employment Law of 1972. This meant above all an increase in the number of people eligible for state unemployment assistance. The increase may have worked as a wage premium, i.e., as an incentive to some labor force groups (in particular youth and females) to join the labor force and/or to stay in it more permanently than before. ${ }^{7}$ The result of the 1972 Law (if any) would consequently show up as less cyclical variation in labor force participation for the groups most affected by the

3 Annual data is used simply because age-specific unemployment rates by sex are not available prior to 1976.

4 Institutional and other secular factors have been studied in the context of time series analysis of labor force participation behavior in Finland by Hilpinen (1976), Köngäs (1978), and Nybergs (1978). Santamäki (1980) estimates equations which are more similar to (3) and (4). However, her results are not directly comparable with ours, among other things because she uses quarterly data and is therefore forced to use the overall unemployment rate as aggregate demand variable in the participation equation. On the other hand, in her counterpart equation to ( $r$ ), she peculiarly enough, utilizes quarterly unemployment rates for age-sex groups, which she has constructed from annual data. That is also done by Petramaa and Wiren (1978) in estimating an equation roughly similar to (4). Note, however, that none of the previous studies did introduce the dummy D in their estimating equations.

5 Inclusion of e.g. birth rates in eq. (3) for females is not warranted because maternity and labor force participation decisions are likely to be jointly determined. The same applies evidently to variables reflecting decisions of taking on further education or of emigration, too. Note also that the growing opportunities for women due to the expansion of the tertiary sector are probably soaked by the trends rather than captured by cyclical changes in prime male unemployment.

6 Michael (1983) contains a discussion of why the causation a priori is ambigious. He also presents evidence (for the U.S.) that women's labor force participation Granger-causes measures of divorce, marriage, men's income, schooling attainment, and is caused by fertility.

7 This will be considered in some more detail on pp. 114-117. 
change in eligibility rules. Another dummy equal to unity as from 1976 is included for purely technical reasons, that is to reflect changes in the levels due to the changes in the implementation of the Labour Force Survey which took place in that year. The changes have been estimated to have brought about an increase in the labor force participation rate of the 15-24 category (both sexes) by about 4 percentage points, and a decline for the group of people aged 55-64 by about 6.5-7 percentage points. ${ }^{8}$ The latter decrease is explained mainly by a redefinition of disability in the Labour Force Survey as from 1976. Unfortunately the change in the Survey happents to coincide with the severe recession during the end of the period and this dummy may therefore also capture other influences.

From (1) it follows directly that we can decompose cyclical changes in E/P into: ${ }^{9}$

$$
\left(\alpha_{1}+\alpha_{2} \mathrm{D}\right)+\left(\beta_{1}+\beta_{2} \mathrm{D}\right),
$$

the first term showing the response in participation to a one-point change change in the prime-age male unemployment rate, and the second term giving the response in the employment to labor force ratio.

This decomposition of the cyclical response to changes in PU in the case of females is set out in Table 1. Here one is struck by the magnitude of the change in the cyclical sensitivity across the two subperiods. Prior to 1972 a one-point decline in PU increased the labor force participation rate of females aged 25 to 34 by 2.3 percent. For prime-age females the corresponding increase was 1.6 percent. After 1972 the associated change in the labor force participation rate is considerably reduced, i.e., statistically not different from zero for those aged 30 to 44 and 1.6 percent for the $25-29$ group. The increase in the response in $\mathrm{L} / \mathrm{P}$ for

T a b l e 1. Females(a)

\begin{tabular}{lcccccc}
\hline \multirow{2}{*}{ Age group } & \multicolumn{2}{c}{$\mathrm{E} / \mathrm{P}$} & \multicolumn{2}{c}{$\mathrm{L} / \mathrm{P}$} & \multicolumn{2}{c}{$\mathrm{E} / \mathrm{L}$} \\
& $1965-71$ & $1972-81$ & $1965-71$ & $1972-81$ & $1965-71$ & $1972-81$ \\
\hline \multirow{2}{*}{$15-19$} & 2.03 & 5.58 & 1.13 & 1.13 & 0.90 & 4.45 \\
& $(1.18)$ & $(1.29)$ & $(0.89)$ & $(0.89)$ & $(0.78)$ & $(0.94)$ \\
$20-24$ & 1.46 & 1.48 & 0.75 & 0.15 & 0.71 & 1.33 \\
& $(0.40)$ & $(0.60)$ & $(0.33)$ & $(0.49)$ & $(0.22)$ & $(0.34)$ \\
& 2.85 & 1.62 & 2.26 & 1.03 & 0.59 & 0.59 \\
& $(0.48)$ & $(0.72)$ & $(0.47)$ & $(0.71)$ & $(0.12)$ & $(0.12)$ \\
& 2.34 & 0.55 & 2.34 & 0.55 & - & - \\
$30-34$ & $(0.50)$ & $(0.76)$ & $(0.50)$ & $(0.76)$ & & \\
& 1.81 & 0.41 & 1.63 & 0.04 & 0.18 & 0.37 \\
$35-44$ & $(0.51)$ & $(0.77)$ & $(0.51)$ & $(0.77)$ & $(0.05)$ & $(0.07)$ \\
& 1.58 & 1.58 & 1.21 & 1.21 & 0.37 & 0.37 \\
$45-54$ & $(0.33)$ & $(0.33)$ & $(0.32)$ & $(0.32)$ & $(0.07)$ & $(0.07)$ \\
& 1.40 & 4.25 & 1.10 & 3.95 & 0.30 & 0.30 \\
$55-59$ & $(0.87)$ & $(1.29)$ & $(0.85)$ & $(1.27)$ & $(0.21)$ & $(0.21)$ \\
& 3.26 & 7.48 & 2.84 & 7.75 & 0.42 & -0.27 \\
$60-64$ & $(2.04)$ & $(3.11)$ & $(2.01)$ & $(3.06)$ & $(0.36)$ & $(0.54)$ \\
& & & & & & \\
& & & & & & \\
& & & & & &
\end{tabular}

a. Numbers in parentheses are standard errors

8 TY 1976: 22, p. 13.

9 To save space we refer to the original paper on details about estimation and selection of final specifications. The estimates from the preferred versions are set out in an appendix available upon request. Here we focus on a more comprehensive presentation of our results. 
the category 60 to 64 years old is 2.8 and 7.7 in $1965-71$ and $1972-81$, respectively. This is furthermore combined with hardly any change at all in unemployment.

During 1965-71 over 70 percent of the cyclical swings in the E/P ratios for women over 25 years old came from changes in participation. Also in the case of female youth did participation account for about half of their cyclical fluctuations in their E/P ratios. After 1972 the picture is dramatically different. Now the labor force participation of women under the age of 45 is more or less independent of cyclical factors. Consequently our estimates suggest that »discouraged worker effects» were much stronger prior to 1972, and that after 1972 such effects are only found for women over 45 years old.

Turning now to Table 2 for males, we may first note that there are some signs of changing cyclical sensitivity here too, albeit only in the case of the youngest and the oldest age groups. Compared with females cyclical fluctuations in participation contribute, as expected, vastly less to the variation in E/P for all male age categories, except the old.

From Tables 2 and 3 it is thus evident that there is rather great variation in cyclical responsiveness across age-sex groups as well as that there have been major changes in the response pattern over time. In Table 3 below the relative importance of different age-sex categories for the cyclical movements in the employment to population ratio is illustrated by weighting the estimates from Tables 2 and 3 by each age-sex group's share of the total population aged 15 to 64 . The first row gives the aggregate change in the proportion of the population employed due to a decrease in PU by one percentage point. The elasticities for both subperiods are remarkably high, a one-point decrease in prime-age unemployment generating a $2-2.5$ percent increase in overall $\mathrm{E} / \mathrm{P}$. Of this increase no less than one percent derives from an increase in participation. The contribution of youth, adults, the old and females are set out in the following rows. We may note that the young (15-24), comprising less than thirty percent of the population between 15 and 64 , account for about forty percent of the cyclical variations in the total E/P.

$\mathrm{T}$ a b 1 e 2. Males

\begin{tabular}{lcccccc}
\hline Age group & \multicolumn{2}{c}{$E / P$} & \multicolumn{2}{c}{$\mathrm{L} / \mathrm{P}$} & \multicolumn{2}{c}{$\mathrm{E} / \mathrm{L}$} \\
& $1965-71$ & $1972-81$ & $1965-71$ & $1972-81$ & $1965-71$ & $1972-81$ \\
\hline \multirow{2}{*}{$15-19$} & 4.90 & 7.40 & 1.52 & 1.52 & 3.38 & 5.88 \\
& $(1.16)$ & $(1.25)$ & $(0.94)$ & $(0.94)$ & $(0.68)$ & $(0.82)$ \\
$20-24$ & 2.44 & 3.31 & 0.30 & 0.30 & 2.14 & 3.01 \\
& $(0.56)$ & $(0.63)$ & $(0.38)$ & $(0.38)$ & $(0.41)$ & $(0.50)$ \\
$25-29$ & 1.74 & 1.74 & 0.16 & 0.16 & 1.58 & 1.58 \\
& $(0.21)$ & $(0.21)$ & $(0.15)$ & $(0.15)$ & $(0.15)$ & $(0.15)$ \\
$30-34$ & 0.97 & 0.80 & - & - & 0.97 & 0.80 \\
& $(0.10)$ & $(0.14)$ & & & $(0.10)$ & $(0.14)$ \\
$35-44$ & 1.07 & 1.07 & 0.07 & 0.07 & 1.00 & 1.00 \\
& $(0.08)$ & $(0.08)$ & $(0.08)$ & $(0.08)$ & & \\
$45-54$ & 1.39 & 1.47 & 0.32 & 0.32 & 1.07 & 1.15 \\
& $(0.25)$ & $(0.27)$ & $(0.21)$ & $(0.21)$ & $(0.14)$ & $(0.17)$ \\
$55-59$ & 0.07 & 2.24 & -0.88 & 1.03 & 0.95 & 1.21 \\
& $(0.66)$ & $(0.92)$ & $(0.56)$ & $(0.82)$ & $(0.35)$ & $(0.43)$ \\
$60-64$ & 1.32 & 5.31 & - & 5.16 & 1.32 & 0.15 \\
& $(0.35)$ & $(1.24)$ & & $(1.12)$ & $(0.35)$ & $(0.53)$ \\
\hline
\end{tabular}


$\mathrm{T} \mathrm{a} \mathrm{ble} \mathrm{3.} \mathrm{The} \mathrm{contribution} \mathrm{of} \mathrm{demographic} \mathrm{groups} \mathrm{to} \mathrm{cyclical} \mathrm{variation} \mathrm{in}$ the employment to population ratio

$1965-71$

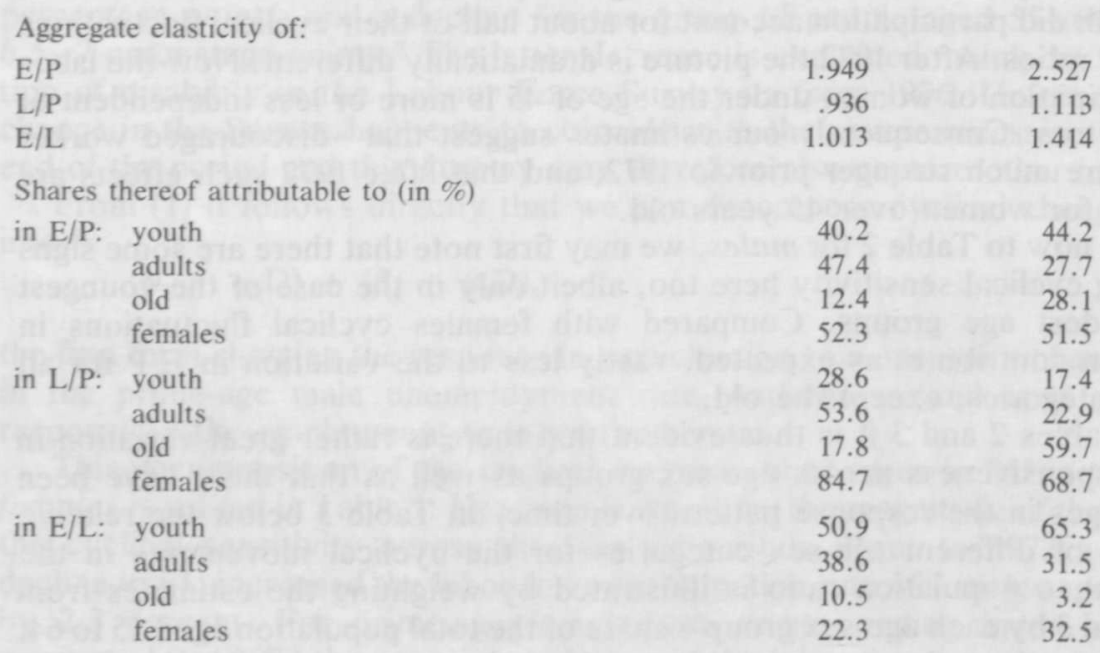

This is foremost due to their disproportionately high share of the fluctuations in the $\mathrm{E} / \mathrm{L}$ ratio. During the seventies the old have had a percentual share of the participation fluctuations which is two times as great as their population share, while the old contribute hardly at all to variations in total employment.

There is no striking difference between the sexes as totals. The shares are as a matter of fact roughly equal in both subperiods. Female adults (aged 25 to 54) do still account for a greater share of the variation in $\mathrm{E} / \mathrm{P}$ than male adults during the $70 \mathrm{~s}$ but the difference has narrowed. Young males contribute more than twice as much to the cyclical variation than women whereas old males contribute considerably less than their female counterparts.

The effect of the change in the demographic composition of the population appears to be minor. We computed the elasticities w.r.t. E/P using the (average) population shares from $1972-81$ on the $1965-71$ estimates and vice versa. The resulting hypothetical estimates, 1.9 and 2.7 , indicate that the middle aging of the population has slightly reduced the cyclical variability.

\section{Long-run changes in different demographic groups' success} in the labor market

Although public concern ultimately lies with the levels of unemployment of the total economy as well as of different groups, in order to understand the determinants of unemployment rates and differences in the rates between various groups, one has to examine the underlying flows of individuals between the stocks of employment, unemployment and out of the labor force statuses. A convenient way of undertaking such an analysis is to look at the transition rates between different labor market states.

Denote the states of employment, unemployment and not in the labor force by $\mathrm{E}, \mathrm{U}$ and $\mathrm{N}$, respectively. Next we denote the gross flow from employment to unemployment as a proportion of the original state (employment) by $e u$, the gross flow from unemployment to not in the labor force by un, and so on. We then 
have nine transition rates, three of which represent no change in the state occupied.

As already indicated knowledge of transition rates may help us to out principal determinants of the unemployment rates. In studies of the effects of various policy measures, institutional or demographical changes focusing on the possibly counteracting effects on the different transition rates may be of great help for drawing conclusions of the outcomes for different labor market groups. ${ }^{9}$ But the transition rates approach may also shed some light on the issues in this paper.

They are given under their arguments in (9):

$$
\begin{array}{r}
\mathrm{U} / \mathrm{L}=\mathrm{f}(\mathrm{eu}, \text { en, ue, un, nu, ne }) \\
++-++- \\
\mathrm{E} / \mathrm{L}=\mathrm{g}(\mathrm{eu}, \mathrm{en}, \mathrm{ue}, \mathrm{un}, \mathrm{nu}, \mathrm{ne}) \\
-+++-+ \\
\mathrm{E} / \mathrm{P}=\mathrm{h}(\mathrm{eu}, \text { en, ue, un, nu, ne }) \\
\mathrm{L} / \mathrm{P}=\mathrm{j}(\mathrm{eu}, \text { en, ue, un, nu, ne })
\end{array}
$$

A change in $e u, u e$, en or ne means that the unemployment rate and the employment to population ratio move in opposite directions (whereas the labor force participation rate may go in any direction). For a simultaneous change in the same direction (in $\mathrm{U} / \mathrm{L}, \mathrm{E} / \mathrm{P}$ and $\mathrm{L} / \mathrm{P}$ ) to occur there has to be a change in the transition rates $u$ and/or $n u$.

Let us now consider the possible implications of the extended coverage of the unemployment assistance system due to the 1972 Employment Law on different transition rates. Alternatively one may of course think of the implications of the extended coverage of the unemployment benefit systems upheld by the unions funds in the same terms.

\section{Transitions from unemployment (ue and un)}

A large body of theoretical research predicts that an increase in the benefit to (net) wage income ratio leads to an increase in the reservation wages and hence to longer periods of search. This conclusion obviously follows also for extended coverage (although the main direct impact presumably would be on the composition of the unemployment stock). However, it should be recognized, first, that the prediction of increases in reservation wages rest on the assumption that job offers are always available to the searcher, which may be called into question (see e.g. Atkinson, 1981). Secondly, although ue may decrease for some fraction of the unemployed it may in fact increase for others (Burdett, 1979, Mortensen, 1977). This is because jobs are not permanent and some searchers, in particular those who are near exhaustion of their benefits or do not receive benefits at all, will become eligible for benefits in the future by accepting offers now.

Transitions from unemployment to not in the labor force, are likely to be affected by an extension of coverage as well, as it will reduce discouraged job search (see for instance Lippman and McCall, 1976).

\section{Transitions from employment (eu and en)}

Feldstein (1976) has argued that not only does unemployment insurance benefits constitute a subsidy to search but also to employers in that part of their costs associated with temporary lay-offs are subsidized. We would not, though, put too much weight on this argument in the case of the Finnish labor market, 
firstly, because temporary lay-offs are relatively rare, and secondly because it is hard to imagine that the changes in the unemployment insurance system have any tangible effects on the other forms of separations from employment. The effect of extended coverage, if any, on transitions from employment to not in the labor force states would probably be negative, because of the reduced discouragement.

\section{Transitions into the labor force ( $n u$ and ne)}

Curiously enough, the impact of unemployment insurance on participation has gained very little interest; a notable exception is Hamermesh (1979). Yet it is conceivable that an extension of entitlement to unemployment insurance benefits, at least for certain groups, would act as a wage premium, i.e., make participation more attractive as the compensation for employment now also includes the chance of becoming eligible for unemployment benefits or assistance. Especially in the case of the extended coverage of unemployment assistance of 1972, when some categories (females and youth) became immediately eligible for assistance (that is, after a waiting perioed of five days) when entering the unemployment status from out of labor force statuses, would we expect an increase in the transition $n u$ to have occurred.

Clearly similar considerations could lead one to expect a reduction in transitions un due to the extended coverage. With regard to ne theory appears to provide no predictions.

All in all, theory suggests, although far from convincingly, that the extended coverage of unemployment insurance systems may give rise to an increase in unemployment rates, since the transitions into and out of unemployment are all predicted to increase and decrease, respectively. As for labor force participation the reduced discouragement of job search in conjunction with the encouraged labor force entry are likely to increase it. What about employment, i.e. the fraction of the population employed? Here we may note that a decrease results only in the case that changes in the transition rates $e u$ and $u e$ dominate changes in the other transition rates en, un, nu (and ne). Moreover, only in the case that the major impact is on transitions $u n$ and $n u$, that is on participation, do we get the result that unemployment and participation rates as well as the employment to population ratio go up (or down) simultaneously. Other configurations of U/L, $\mathrm{L} / \mathrm{P}$ and $\mathrm{E} / \mathrm{P}$ can be matched with several, a priori equally likely, combinations of changes in the transition rates.

In Table 4 the percentual annual changes in the components of the female employment to population ratios (as measured by the trends, $\mathrm{T}$ and DT, in our regressions) are given. (Due to space limitations the corresponding, but less interesting, table for males is omitted.)

Since we have controlled for cyclical factors, the trends capture various secular influences mentioned earlier. Particularly noteworthy here are the changes across subperiods. Prior to 1972 there was no secular change in unemployment rates of women, whereas from 1972 onwards there is a positive trend in them for all age groups, save teenagers. For all groups, except the two oldest categories, is this secular increase in unemployment associated with a simultaneous secular increase in labor force participation rates as well as employment to population ratios. As noted above, this is consistent only with $a$ decrease in the transitions from unemployment to out of labor force status and /or an increase in the transitions of individuals from not in the labor force status to unemployment. Naturally, this does not exclude the possibility that other transition rates may have changed as well, but they must have done so significantly less than $n u$ and $u n$.

Turning now to some speculation about the possible causes of the changes in un ad nu we take the extended coverage of the unemployment assistance system 
$\mathrm{T}$ a b 1 e 4. Annual trend growth in $\mathrm{E} / \mathrm{P}, \mathrm{L} / \mathrm{P}$ and $\mathrm{E} / \mathrm{L}$, females (in \%).

\begin{tabular}{|c|c|c|c|c|c|c|}
\hline \multirow[t]{2}{*}{ Age group } & \multicolumn{2}{|c|}{$\mathrm{E} / \mathrm{P}$} & \multicolumn{2}{|c|}{$\mathrm{L} / \mathrm{P}$} & \multicolumn{2}{|c|}{$\mathrm{E} / \mathrm{L}$} \\
\hline & $65-71$ & $72-81$ & $65-71$ & $72-81$ & $65-71$ & $72-81$ \\
\hline $15-19$ & -4.8 & -2.3 & -4.8 & -2.3 & - & - \\
\hline $20-24$ & - & 0.3 & - & 0.7 & - & -0.4 \\
\hline $25-29$ & 1.4 & 1.0 & 1.4 & 1.4 & - & -0.4 \\
\hline $30-34$ & 2.2 & 1.0 & 2.2 & 1.0 & - & - $^{*}$ \\
\hline $35-44$ & 1.3 & 1.2 & 1.3 & 1.3 & - & -0.1 \\
\hline $45-54$ & - & 1.0 & - & 1.3 & - & -0.3 \\
\hline $55-59$ & - & -0.3 & - & 0.4 & - & -0.7 \\
\hline $60-64$ & -2.1 & -3.2 & -2.1 & -2.1 & - & -1.1 \\
\hline
\end{tabular}

* Note that the shiftdummy equal to unity as from 1972 was negative and significantly different from zero.

as of 1972 as one top candidate. Clearly this implies that we make the bold assumption that the extension's effect foremost was on participation and to a much lesser extent on for instance unemployment duration. Is that at all plausible?

We would expect an increase in unemployment benefits or an extension of coverage to affect adult females more than other groups, because if females are members of families with two adults in the labor force, their earnings are mostly lower than their spouses', and so their replacement ratios are affected more. Thus the decreases in transition rates $u e$ and $u n$ and increases in $n u$ would be more pronounced for women, and particularly for those who are married.

The wage premium effect of unemployment assistance may have been reinforced by other factors contributing to an increased labor force attachment of women. For instance if an individual's age-earnings profile is relatively flat, then a lenghty spell of unemployment or out of the labor force is not likely to have large adverse effects on the individual's future earnings prospects. The increasing proportion of females with better education working in jobs requiring more specific skills and which have less flat age-earnings profiles has probably increased the permanency of labor force attachment. It should also be noticed that there is evidence from other countries as well of an secular increase in the female probability of entering the labor force and a simultaneous decrease in the probability of exit; e.g for Sweden Pettersson (1981) and Gustafsson and Jacobsson (1983) and for United States Corcoran (1979). Search theory predicts that the longer a person is planning to stay in the labor force the higher the optimal reservation wage will be (Lippman and McCall (1976). Consequently, there will be an increase in unemployment duration, as the transition ue decreases, and also a lower inflow $(n u)$ into unemployment because of less re-entrants. Although the experience of especially females seems to be in accordance with this horizon effect, this only arouses the question as to why they have a longer planning horizon than before. One conceivable explanation is the change from joint to individual income taxation of couples, but that was introduced as from 1976, and the changes in labor market behavior have been successive, and the major changes can be dated to around 1972 .

\section{Concluding remarks}

We think the principal lesson borne out by this exercise is that taking into account both employment and labor force participation variations is essential in 
order to understand the short-run, cyclical movements in unemployment in the Finnish labor market, as well as the secular changes in unemployment that have taken place during the last two decades. Groups with higher than average unemployment rates respond to an increase in available jobs by increasing their participation, thereby giving rise to the impression that it is exceedingly hard to reduce their unemployment rates. This is especially the case with teenagers and the old. We have also found that prior to 1972 females of nearly all ages belonged to the category displaying substantial fluctuations in participation, but that this no longer holds as from 1972. This is consistent with a reduced discouragement of women when demand slackens.

It appears that the extension of the unemployment assistance system of 1972 may have reinforced the tendency towards a higher degree of permanency in female labor force attachment, and that the extension did not only contribute to an increase in unemployment but also to an even greater increase in participation and consequently to an increase in employment as well. Other factors have probably been important, too, but too little is known about their interaction for us to make strong claims about which is (are) the causa causans of the simultaneous increase in employment and unemployment.

However, this suggests that the unemployment figures between the period before 1972 and the period after, are not directly comparable, or put in another way, the remarkable increase in the overall unemployment rate during the seventies is partly due to the fact that some of the earlier hidden unemployment has become measurable. We should also recognize that the reduced cyclical variation in participation of adult females may reflect changes in the composition of the female labor force. They are more educated, hold jobs requiring more skilled labor and permanent attachment to the labor market.

\section{References}

Atkinson, A. B. (1981). Unemployment benefits and incentives. In: The economics of unemployment in Britain edited by J. Creedy. Butterworths.

Burdett, K. (1979). Unemployment as a search subsidy. Economic Inquiry.

- Kiefer, N. M.; Mortensen, D. T. and Neumann, G. R. (1984). Earnings, unemployment, and the allocation of time over time. Review of Economic Studies.

Clark, K. B. and Summers, L. H. (1979). Labor market dynamics and unemployment: a reconsideration. Brookings Papers on Economic Activity.

- and Summers, L. H. (1981). Demographic differences in cyclical employment variation. Journal of Human Resources.

- and Summers, L. H. (1982a). The dynamics of youth unemployment. In: The youth labor market problem: its nature, causes, and consequences, edited by R. B. Freeman \& D. Wise. NBER. Chicago University Press.

- and Summers, L. H. (1982b). Unemployment insurance and labor market transitions. In: Workers, jobs, and inflation, edited by M. N. Baily. Brookings.

- and Summers, L. H. (1982c). Labor force participation: timing and persistance. Review of Economic Studies.

Corcoran, M. (1979). Work experience, labor force withdrawals, and women's wages: empirical results using the 1976 panel of income dynamics. In: Women in the labor market, edited by C. Lloyd, E. Andrews and C. Gilroy. Columbia University Press.

Ehrenberg, R. G. (1980). The demographic structure of unemployment rates and labor market transition probabilities. In: Research in labor economics, Vol. 3, edited by R. G. Ehrenburg. JAI Press.

Feldstein, M. S. (1973). Lowering the permanent rate of unemployment. A study prepared for the use of the US Joint Economics Committee. Washington D. C.

Freeman, R. B. and Medoff, J. L. (1982). The youth labor market problem in the United States: an overview. In: The youth labor market problem: its nature, causes, and consequences, edited by R. B. Freeman and D. Wise. NBER, Chicago University Press. 